\title{
Carbon dioxide concentrations and nest ventilation in nests of the leaf-cutting ant Atta vollenweideri
}

\author{
C. Kleineidam ${ }^{1,2}$ and F. Roces ${ }^{1}$ \\ 1 Theodor-Boveri-Institut, Lehrstuhl für Verhaltensphysiologie und Soziobiologie, Am Hubland, D-97074 Würzburg, Germany, \\ e-mail:kleineidam@biozentrum.uni-wuerzburg.de; roces@biozentrum.uni-wuerzburg.de \\ 2 Parque Nacional Río Pilcomayo, CP 3613 Laguna Blanca, Provincia de Formosa, Argentina
}

Summary. Microclimatic conditions in the giant nests of the leaf-cutting ant Atta vollenweideri were experimentally examined to address the question whether increasing concentrations of the respiratory gases affect colony respiration. Measurements of $\mathrm{CO}_{2}$ concentrations of less than $2.8 \%$ at different depths inside mature field nests indicated good ventilation, even at $2 \mathrm{~m}$ depth. Passive ventilation was driven by wind and promoted by the shape of the nest. It did not influence nest temperature nor relative humidity. During rain and flooding, small colonies closed all nest openings to protect the nest from excessive water influx and damage. Measurements in a small nest indicated that, as a consequence of closure, the $\mathrm{CO}_{2}$ concentration increased rapidly. This situation was simulated in the laboratory, using a small colony of Atta sexdens as a model system. Colony respiration rates were shown to be reduced as a function of increasing $\mathrm{CO}_{2}$ concentration. Based on literature data on ant respiration, it is suggested that the respiration of the symbiotic fungus was reduced, and not that of the ants. Since the brood of leaf-cutting ants feeds exclusively on the fungus, reduced nest ventilation and its effects on respiration rates may compromise colony growth. While mature nests provide the colony with good microclimate under all weather conditions during summer, developing colonies are confronted with a tradeoff between minimizing the risk of inundation and assuring adequate gas exchange inside their nests.

Key words: Leaf-cutting ants, carbon dioxide, nest ventilation, colony growth, respiration.

\section{Introduction}

Most species of social insects build nests that protect the colony and especially the brood against predators and provide a microclimate suited to the colony's needs. Microclimatic variables can be independently regulated only within a limited range. Regulation of one parameter to its optimum will often drive another parameter to its suboptimum. For example, nest temperatures higher than ambient temperature require some kind of nest insulation and can thus often be achieved only at the expense of gas exchange (Seeley and Heinrich, 1981; Hölldobler and Wilson, 1990). Colony's humidity demand can also conflict with the necessity for gas exchange (Scherba, 1958; Collins, 1969; Noirot, 1970). Tradeoffs in regulation of microclimatic conditions are therefore expected to occur, and the insect society has to balance its efforts accordingly.

Gas exchange between nest and environment is essential. Due to colony respiration considerable amounts of $\mathrm{O}_{2}$ are consumed and $\mathrm{CO}_{2}$ produced. In closed dwellings this leads to hypoxic (low oxygen) and hypercapnic (high carbon dioxide) conditions, as is also observed in nonsocial insects (Howarth, 1983; Anderson and Ultsch, 1987). Several investigations report $\mathrm{CO}_{2}$ concentrations ranging from $0.05 \%$ (normal) to $15 \%$ in nests of social insects (Lüscher, 1956; Es'Kov, 1974; Matsumoto, 1977; Anderson and Ultsch, 1987; Kirchner, 1998).

With the exception of termites (Lüscher, 1961) and bees (Simpson, 1961; Seeley, 1974; Southwick and Moritz, 1987), little is known about the regulation of respiratory gases in the nests of social insects. With up to several million individuals, the colonies of the leaf-cutting ant Atta vollenweideri are one of the largest social insect societies (Weber, 1972). Once clearly established, a nest reaches an average age of about 10 years (Jonkman, 1978; Jonkman, 1980a). Without nest ventilation, a reduction in the availability of $\mathrm{O}_{2}$ due to the respiration of both fungus and ants in the limited space of the nest chambers will be associated with a proportional increase in $\mathrm{CO}_{2}$. Hypoxic and hypercapnic conditions may affect colony respiration, and the existence of active and/or passive mechanisms for nest ventilation is therefore expected. It is impor- 
tant to note that while the ability to sense $\mathrm{CO}_{2}$ is widespread in insects, no biological system is known to sense the $\mathrm{O}_{2}$ of the ambient air. As a consequence, $\mathrm{CO}_{2}$ is the biologically relevant parameter providing the ants with indirect information about the essential $\mathrm{O}_{2}$ availability. Leaf-cutting ant workers possess the ability to measure not only the relative but also the absolute $\mathrm{CO}_{2}$ concentrations with special sensory organs (Kleineidam and Tautz, 1996), an unusual feature that points to the fact that information about actual $\mathrm{CO}_{2}$ concentrations is of great importance for the ants.

During the rainy season, the habitat of the leaf-cutting ant Atta vollenweideri is regularly flooded. Flooding often confines the ants to their nests and prevents them from foraging for plant material (Jonkman, 1979). While mounds of mature colonies protect colonies from excessive water influx because all the nest openings are located more than $20 \mathrm{~cm}$ above the surrounding, small developing colonies are vulnerable to flooding due to the small size of their mounds. Thus, when facing strong precipitation and flooding, they tightly close all nest openings with twigs and clay crumbs (Jonkman, 1980 a), a situation which often needs to be maintained for several days. Protection of the colony against water influx constrains nest ventilation and could consequently affect colony respiration.

The enormous colony size, the uniform architecture of the mound and the well known arrangement of the subterranean nest chambers (Eidmann, 1935; Daguerre, 1945; Jonkman, 1980 b) make Atta vollenweideri an excellent object for studying the control of nest climate.

The aim of the present study was to assess the influence of nest ventilation on microclimate inside the nest of the leaf-cutting ant Atta vollenweideri. $\mathrm{CO}_{2}$ concentrations, temperature and humidity were measured in field nests as a function of wind velocity. Furthermore, the potential tradeoff between protection of the nest against inundation by closing nest openings and the need of gas exchange was examined in one small colony.

\section{Methods}

The field experiments were done in the National Park Río Pilcomayo, Formosa Province, Argentina $\left(58^{\circ} \mathrm{W} ; 25^{\circ} \mathrm{S}\right)$. Measurements were performed in different nests during December of 1997 to February of 1998 (across weather conditions). The annual average temperature in this region is $23{ }^{\circ} \mathrm{C}$ and the mean precipitation is $1200 \mathrm{~mm}$ (mean relative humidity $79 \%$ ). Precipitation exceeds evaporation in all months of the year except in August (Pujalte et al., 1995).

\section{Nest characteristics}

In order to assess the influence of nest size on $\mathrm{CO}_{2}$ concentration and nest ventilation, different nests, representing the extremes in the size range observed in the research area, were chosen. Seven mature nests and one small nest (in it's second year after foundation) were investigated. Since the internal structure strongly depends on nest age, it was crucial to perform measurements in small nests of known age. This was possible only for one small nest which had been identified during a previous field trip.

The mound volume was calculated using either the formula for a cone $\left(\mathrm{V}=\pi \mathrm{r}_{1} \mathrm{r}_{2} \mathrm{~h} / 3\right)$ or a dome (sphere segment) $\left(\mathrm{V}=\pi \mathrm{h}\left(3 \mathrm{r}_{1} \mathrm{r}_{2}+\mathrm{h}^{2}\right) / 6\right)$, depending on its shape. The height $(\mathrm{h})$ of the nest was defined as the dif- ference between ground level and top of the mound. Ground level was considered as the level of the surrounding area of the nest. The radii $\left(\mathrm{r}_{1} ; \mathrm{r}_{2}\right)$ were half of the largest and smallest diameter of the nest, respectively. The size of the nest mound can be used as criterion for the maturity of a colony (Jonkman, 1980a). The mound volume was therefore used to estimate the nest volume (chambers and tunnels), although the key parameter is the below-ground volume which was not possible to assess. Old nests may contain dump chambers filled with refuse, while mature nests may have more free space in empty chambers at the beginning of maturity. Old colonies are characterized by low foraging activity, thus, only nests with well established foraging trails (more than 3 active trails during a foraging period) were investigated.

The mound of the small nest was described by mapping the heights with a grid of $20 \mathrm{~cm}$. The volume was calculated by adding all cubits. The area of nest openings was calculated using the cross section of the tunnels measured at the narrowest part in the first $10 \mathrm{~cm}$ from the openings with the formula $\mathrm{A}=\pi \mathrm{r}_{1} \mathrm{r}_{2}$. Several measurements were performed in one mature and one small nest. The same two nests were used and are referred to in the text as mature (M) and small nest (S).

\section{Microclimate in the nests}

The concentration of $\mathrm{CO}_{2}$ was measured by IR-absorption with a gas sensor type GS $20 \mathrm{ED} / \mathrm{CO}_{2}$ (Sensor Devices, Germany). Data were logged with a self-made data logger equipped with a micro computer (Tiger Basic), and transferred to a laptop for processing.

Air samples were collected by drilling an iron pipe $1.5 \mathrm{~m}$ into the mound. The pipe could be prolonged for another $1.5 \mathrm{~m}$, thus air samples from up to $3 \mathrm{~m}$ below surface could be taken. The end of the pipe was inserted into a chamber or a tunnel. Cavities in the soil were detected, because the drilling of the probe was much easier when the pipe entered them. Air probes were drawn from cavities at different depths of the nest with a membrane pump (12 V Wisa, Germany) for 3 min with a flow rate of $1.51 \mathrm{~min}^{-1}$. During long term-recordings air probes were taken every 3 hours. In general, the most significant parameters influencing the gaseous environment of cavities are soil porosity, soil moisture (because it alters soil porosity), and the absolute metabolic requirements of the occupants (Withers, 1978). The nests of Atta vollenweide$r i$ are built in heavy clay soil, thus soil porosity and moisture are most unfavorable for exchange of respiratory gases via diffusion. The low porosity and high water content of the clay soil prevented the collection of air samples from locations other than the nest cavities.

The effects of wind on the $\mathrm{CO}_{2}$ concentration inside the nest were investigated by performing simultaneous long-term recordings of wind velocity and $\mathrm{CO}_{2}$ concentration. The measurements were performed on $20 / 21$ February 1998 . The wind velocity was qualitatively indicated by the excursion of a cotton filament and four categories were defined. Zero indicated no-wind, and the category 3 corresponded to approx. $1 \mathrm{~ms}^{-1}$. During $\mathrm{CO}_{2}$ data collection, the filament was observed for $5 \mathrm{~min}$ and the wind velocity was assigned to one of the categories.

In order to investigate the influence of environmental temperature and humidity on nest microclimate, these parameters were recorded during a hot and a dry weather period. Humidity and temperature were recorded with two testing probes (Vaisala HMP 36B) and logged with a Vaisala HMI 36 data processor. On 9 December, two testing probes were introduced via the biggest tunnel in the center of a mature nest $(\mathrm{M})$ at $1 \mathrm{~m}$ and at $0.1 \mathrm{~m}$, respectively. Data were logged every hour for $24 \mathrm{~h}$. On 26 December, humidity and temperature were measured in 12 different tunnels of the mature nest (distributed homogeneously over the mound surface) and all the 6 tunnels of the small nest at a depth of $40 \mathrm{~cm}$ in the afternoon (14:00-16:00 h with similar weather conditions as on 9 Dec.). Wind velocity during daytime was at least $3 \mathrm{~ms}^{-1}$.

\section{Respiration rate of small colonies}

The consequence of reduced exchange of respiratory gases on colony respiration was investigated in a small laboratory colony of Atta sexdens, used as a model for the respiration of Atta vollenweideri. The 
potential effects of species-specific differences in their fungal strains will be addressed in the discussion.

The experiments were done in Würzburg during the summer of 1998. The colony of Atta sexdens, collected in Botucatú, São Paulo, Brazil, was about 3 years old and the fungus garden occupied a volume of about 121 . The colony was reared at $25^{\circ} \mathrm{C}$ and $50 \%$ relative humidity in a $12 \mathrm{~h} / 12 \mathrm{~h}$ photoperiod and fed predominantly with leaves of privet (Ligustrum vulgaris).

The $\mathrm{CO}_{2}$ production of the tightly enclosed colony was measured over time in order to determine colony respiration rate as a function of increasing $\mathrm{CO}_{2}$ concentration. One-half of the colony (two boxes) was used in all experiments. It was kept in a closed-loop system for either 2 or 3 days. During this period, the volume of the fungus decreased from 4.31 to 3.11 , estimated by the percentage of spongy fungal mycelium occupying the box. The closed-loop system simulated the conditions of a small colony during a rainy period when all nest openings are closed. The total volume of the closed-loop system was 11.31 , composed of a plastic box with a tube connection to a $\mathrm{CO}_{2}$ analyzer and a pump. 0.41 of clay crumbs saturated with water was added to the plastic box. By continuously pumping air at a rate of $11 \mathrm{~min}^{-1}$ through the closed-loop system, air was mixed in the box and renewed in the measuring chamber of the $\mathrm{CO}_{2}$ analyzer. In all experiments the $\mathrm{CO}_{2}$ concentrations inside the closed system were measured every $5 \mathrm{~min}$ for $160 \mathrm{~min}$. The experiment was repeated 6 times and all data were pooled.

The rate of $\mathrm{CO}_{2}$ absorption by the material (clay and plastic boxes) of the closed-loop system or by dilution in water was determined in control experiments. The colony was removed from the boxes and the $\mathrm{CO}_{2}$ concentration in the empty nest was artificially increased by injecting pure $\mathrm{CO}_{2}$ (a valve was added to avoid hyperpressure). Injection was done with a magnetic valve (Lee Company, USA) every $5 \mathrm{~min}$ for $4 \mathrm{~s}$ with 3 different pressures, resulting in the following flow rates: $246 \mathrm{ml} \mathrm{h}^{-1}(\mathrm{SD} \pm 13.34 \mathrm{ml} ; \mathrm{n}=3), 326 \mathrm{ml} \mathrm{h}^{-1}$ and $380 \mathrm{ml} \mathrm{h}^{-1} \mathrm{CO}_{2}$. Different flow rates were used in order to evaluate the influence of $\mathrm{CO}_{2}$ injection on the rate of $\mathrm{CO}_{2}$ absorption. These flow rates were in the range of the $\mathrm{CO}_{2}$ production rate of the investigated colony. Data were captured using the same protocol as described above. The injected $\mathrm{CO}_{2}$ volume was calculated by multiplying the difference in $\mathrm{CO}_{2}$ concentration between the starting point and after the first hour by the total volume of the closed-loop system (10.9 1).

\section{Results}

\section{Microclimate in the nests}

Morphology of the nest mound and $\mathrm{CO}_{2}$ concentrations at different depths are summarized in Table 1 for the investigated nests. In mature nests, the measured $\mathrm{CO}_{2}$ concentration was significantly lower at a mean depth of $0.61 \mathrm{~m}$ below the normal level than at a depth of $2.07 \mathrm{~m}\left(\mathrm{~T}_{+}=28, \mathrm{p}<0.01\right.$; Wilcoxon matched paired test (Siegel and Castellan, 1988)). There was a high variability in $\mathrm{CO}_{2}$ concentration at both depths (upper depth: $0.78 \% \mathrm{CO}_{2} ; \mathrm{SD} \pm 0.48$; lower depth $\left.1.94 \% \mathrm{CO}_{2} ; \mathrm{SD} \pm 0.77 ; \mathrm{n}=7\right)$. No significant correlation between mound size and $\mathrm{CO}_{2}$ concentration could be found in mature nests (upper depth: Spearmans $\mathrm{R}=-0.52$; $\mathrm{p}=0.29$; lower depth: Spearmans $\mathrm{R}=-0.26 ; \mathrm{p}=0.62)$. In the small nest, the mean $\mathrm{CO}_{2}$ concentration was $2.44 \% \mathrm{CO}_{2}$ $(\mathrm{SD} \pm 1.46 ; \mathrm{n}=23)$ in repeated measurements on different days.

The influence of wind on the $\mathrm{CO}_{2}$ concentration inside the nests was investigated by performing parallel long-term recordings in the mature $(\mathrm{M})$ and the small nest $(\mathrm{S})$. There was a strong negative correlation between wind velocity and $\mathrm{CO}_{2}$ concentration in both nests (Fig. 1). In the mature nest, the correlation coefficient between wind velocity and the $\mathrm{CO}_{2}$ concentration was $\mathrm{R}=-0.82$ at $2 \mathrm{~m}$ depth $(\mathrm{p}<0.05$; Spearmans $\mathrm{R})$, and $\mathrm{R}=-0.85$ at $0.5 \mathrm{~m}$ depth $(\mathrm{p}<0.05$; Spearmans R). In the small nest it reached $\mathrm{R}=-0.92(\mathrm{p}<$ 0.01; Spearmans R). The $\mathrm{CO}_{2}$ concentration increased during no-wind conditions (local time 18:00, Fig. 1) in both nests.

Inflowing air may change the internal nest microclimate concerning temperature and humidity. Figure 2 shows, as an example, the daily course of relative humidity and temperature at two different depths in the mature nest (M). In a tunnel at a depth of $1 \mathrm{~m}$ below zenith of the dome, the temperature and the relative humidity were constant. The mean temperature was $27.5^{\circ} \mathrm{C}$ (range: $27.4-27.6^{\circ} \mathrm{C}$ ) and the mean relative humidity was $95.9 \%$ on this day. Just below the surface of the mound, $0.1 \mathrm{~m}$ down in a tunnel the temperature and relative humidity varied with the daily temperature changes in the savanna. The mean temperature was $33.7^{\circ} \mathrm{C}$ (range: $28.0-40.9^{\circ} \mathrm{C}$ ) with a mean relative humidity of $70.6 \%$ (range $43.4-91.3 \%$ ). In the environment, the mean daily temperature was $31.0^{\circ} \mathrm{C}$ (range: $24.4-36.1^{\circ} \mathrm{C}$ ) $1.5 \mathrm{~m}$ above ground in the shadow, with a mean relative humidity of $71.2 \%$ (range: $52.0-93.2 \%$ ).

Since it was not possible to measure temperature and humidity in a depth of $1 \mathrm{~m}$ inside the small nest, these para-

Table 1. Shape and $\mathrm{CO}_{2}$ concentration at two different depths of seven mature nests measured on different days. Height: Elevation above ground level. Upper depth is the nest area where the fungus garden are expected to occur, lower depth the area corresponding to the dump chambers (Jonkman, 1980 b). Note that the depths are measured from the top of the mound.

\begin{tabular}{|c|c|c|c|c|c|c|}
\hline $\begin{array}{l}\text { Shape of } \\
\text { mound }\end{array}$ & $\begin{array}{l}\text { Mound } \\
\text { volume }\left(\mathrm{m}^{3}\right)\end{array}$ & $\begin{array}{l}\text { Height } \\
\text { (m) }\end{array}$ & $\begin{array}{l}\text { Upper } \\
\text { depth (m) }\end{array}$ & $\begin{array}{l}{\left[\mathrm{CO}_{2}\right] \text { in upper }} \\
\text { depth }(\%)\end{array}$ & $\begin{array}{l}\text { Lower } \\
\text { depth (m) }\end{array}$ & $\begin{array}{l}{\left[\mathrm{CO}_{2}\right] \text { in lower }} \\
\text { depth }(\%)\end{array}$ \\
\hline Dome & 16.1 & 1.0 & 0.5 & 0.83 & 2.0 & 1.96 \\
\hline Dome & 20.2 & 0.9 & 0.5 & 0.07 & 2.0 & 1.10 \\
\hline Dome & $59.8^{\mathrm{a}}$ & 0.9 & 0.4 & 0.29 & 1.9 & 2.50 \\
\hline Dome & 10.9 & 0.7 & 0.8 & 0.83 & 2.0 & 1.59 \\
\hline Dome & 9.3 & 0.6 & 0.9 & 1.53 & 2.4 & 2.79 \\
\hline Mean & 13.2 & 0.87 & 0.61 & 0.78 & 2.07 & 1.94 \\
\hline Std. Dev & 4.1 & 0.16 & 0.19 & 0.48 & 0.17 & 0.77 \\
\hline
\end{tabular}

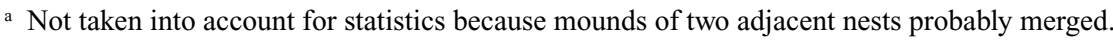



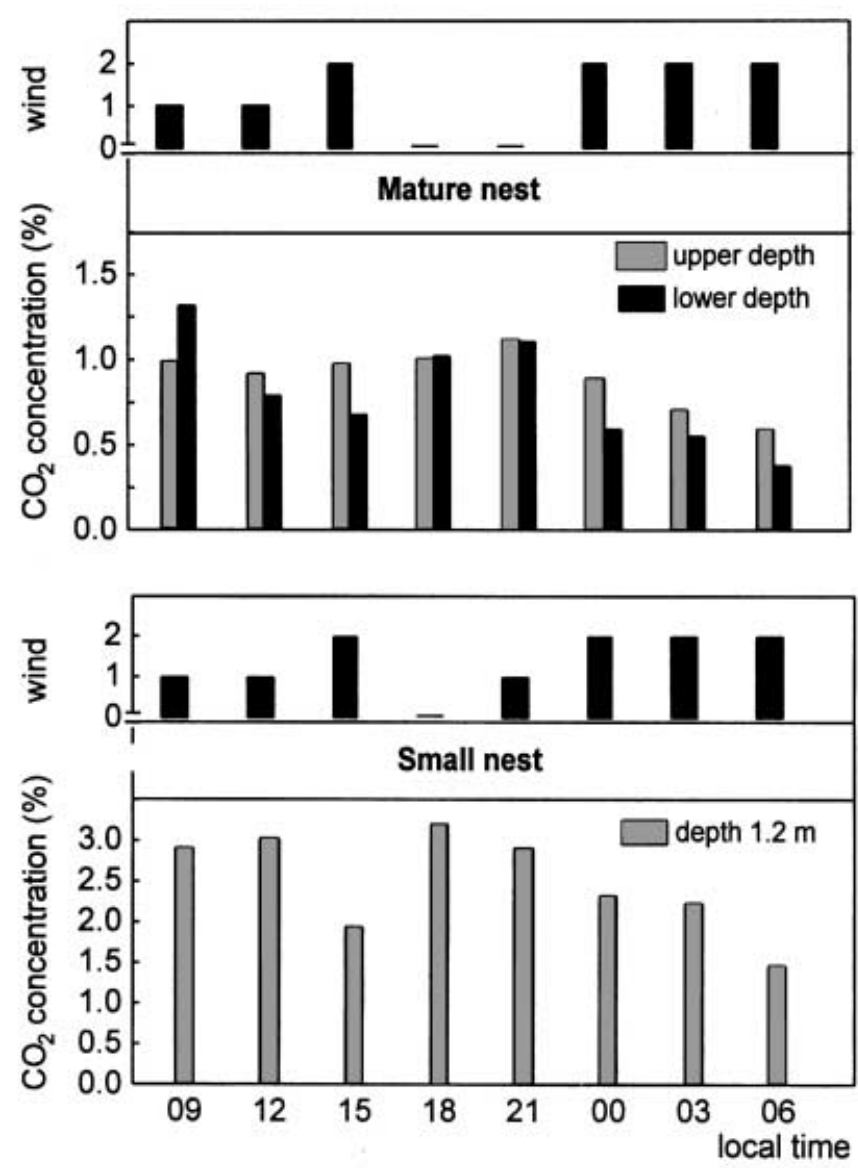

Figure 1. Wind velocity (in categories) and $\mathrm{CO}_{2}$ concentrations during $21 \mathrm{~h}$ in two different nests. Mature nest (upper) with a mean $\mathrm{CO}_{2}$ concentration of $0.80 \%$ at a depth of $2.0 \mathrm{~m}$ and $0.90 \%$ at $0.5 \mathrm{~m}$. Small nest (lower) with a mean $\mathrm{CO}_{2}$ concentration of $2.50 \%$ at a depth of $1.2 \mathrm{~m}$. Note that any increase in wind velocity is followed by a decrease in the $\mathrm{CO}_{2}$ concentration inside the nest and vice versa. The $\mathrm{CO}_{2}$ concentration was measured during $21 \mathrm{~h}$ every $3 \mathrm{~h}$ in a mature nest and with a delay of $20 \mathrm{~min}$ in the small nest

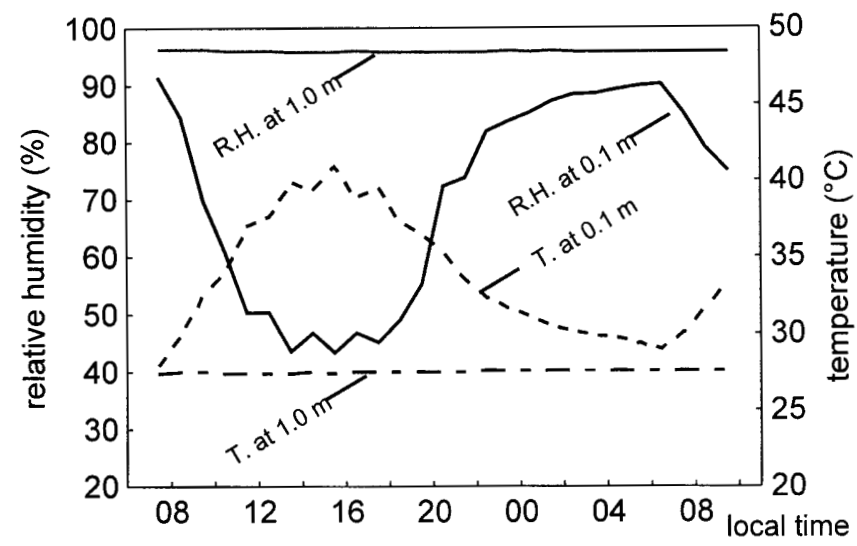

Figure 2. Example of the daily course of relative humidity and temperature in a mature nest. Testing probes were inducted into a tunnel at two different depths, 1.0 and $0.1 \mathrm{~m}$. Note the constant relative humidity and temperature at the lower depth. At $0.1 \mathrm{~m}$, the temperature and the relative humidity followed the daily environmental changes meters were measured comparatively at a depth of $40 \mathrm{~cm}$ in different tunnels of both nests. At $40 \mathrm{~cm}$ depth in the mature nest $(\mathrm{M})$, the temperature was $33.2^{\circ} \mathrm{C}(\mathrm{SD} \pm 1.90 ; \mathrm{n}=12)$ with a relative humidity of $76.0 \%(\mathrm{SD} \pm 15.16 ; \mathrm{n}=12)$. In the small nest (S), in all of the 6 visible tunnels the temperature was $31.5^{\circ} \mathrm{C}(\mathrm{SD} \pm 0.3 ; \mathrm{n}=6)$ with a relative humidity of $93.3 \%(\mathrm{SD} \pm 4.36 ; \mathrm{n}=6)$. Note that the variance of data is much higher in the tunnels of the mature than in the small nest, which had a higher relative humidity, indicating that a greater volume of dry air is flowing through the tunnels of the mature nest.

\section{Nest closure of small colonies}

The small nest was investigated in greater detail since small colonies have the demand of nest closure during strong precipitation and flooding. The occurrence of strong precipitation during the rainy season is, a priori, one important factor influencing nest microclimate. Different behavioral reactions to strong precipitation were observed between small and mature colonies. Several small colonies were observed to react to heavy rain by closing all nest openings. The smallest nests observed (with only one or two entrances) were often completely closed even if protection against flooding seemed to be unnecessary. Building activity at the openings of mature nests was not very pronounced during heavy rain, even though eager transportation of clay crumbs out from the dwellings could be observed after rain at all nests.

The influence of closure on the nest microclimate of the small nest ( $\mathrm{S}$ ) was assessed by measuring $\mathrm{CO}_{2}$ concentrations over a period of 3 days. The nest openings were closed by the ants due to heavy rain in the first hours of the second day (20. Feb.). The ants occluded the nest tunnels by covering the openings with twigs. Water-soaked clay crumbs tamped the remaining cracks. It took only about $1 \mathrm{~h}$ until all 6 openings were closed and about the same time after rain had ceased for reopening them, though to a smaller aperture. Unfortunately the testing probe was also occluded by the ants activity. It had to be removed and was reinserted at the same spot as before.

Occlusion of all nest openings led to a steep increase of $\mathrm{CO}_{2}$ concentration inside the nest (Fig. 3). Over $24 \mathrm{~h}$, the $\mathrm{CO}_{2}$ concentration rose from $1.09 \%$ to $5.69 \%$ (20. Feb.). Therefore the rate of increase in $\mathrm{CO}_{2}$ concentration on this day was $0.19 \% \mathrm{CO}_{2} \mathrm{~h}^{-1}$. The total aperture (cross section of all 6 tunnels summed) was $114 \mathrm{~cm}^{2}$ at the beginning (19. Feb.; 00:00). During rain all tunnels were completely closed (20. Feb.; 01:00-07:00). Eight hours later, the total aperture was $56 \mathrm{~cm}^{2}$ (20. Feb.; 15:00). The absence of wind during the following hours may have contributed to the further increase of $\mathrm{CO}_{2}$ concentration. On the following day the total aperture was $92 \mathrm{~cm}^{2}$.

The conditions prevailing during heavy rain were simulated in an independent experiment by tightly occluding all openings of the small nest with the lower half of plastic bottles. Before occlusion only very few foragers were outside the nest. They were stimulated to return into the nest by irrigating them with water and thus simulating rain. The occlusion 


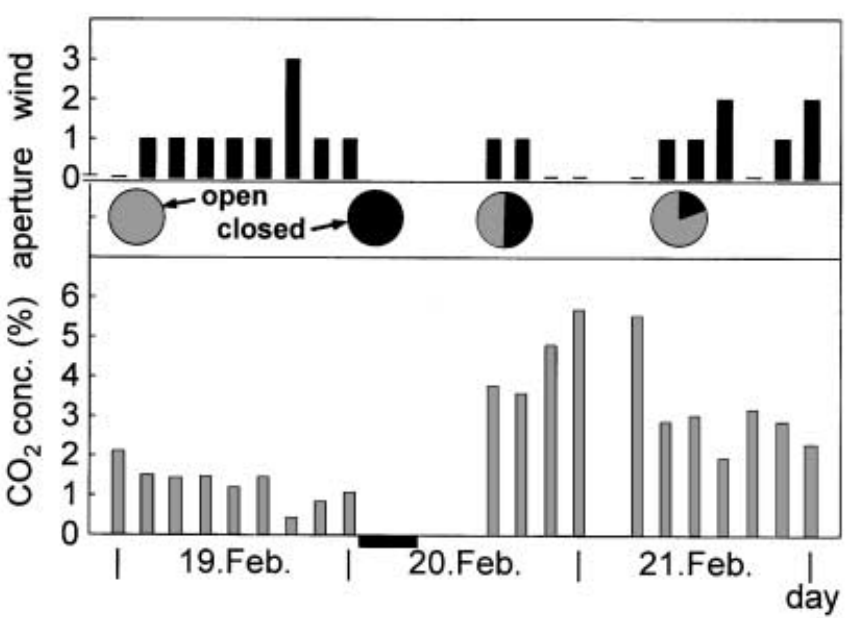

Figure 3. Wind velocity (upper, in categories) and aperture of all nest openings (pie chart; middle), and their correlation with $\mathrm{CO}_{2}$ concentration at a depth of $1.2 \mathrm{~m}$ (lower) in the small nest over a period of 3 days. The horizontal bar on the $\mathrm{x}$-axis indicates heavy rain over $6 \mathrm{~h}$ with $50 \mathrm{~mm}$ precipitation. No data could be taken on 20 Feb. $03: 00-12: 00$ and 21 Feb. 03:00

disturbed the colony only a little at the beginning. As soon as condensed water dropped from the inner wall of the plastic covers, the ants started to close the openings. Figure 4 shows the time-course of $\mathrm{CO}_{2}$ concentration changes, which was observed to rise linearly from $1.88 \% \mathrm{CO}_{2}$ after $30 \mathrm{~min}$ of total occlusion to $3.75 \% \mathrm{CO}_{2}$ after $6 \mathrm{~h}$. The increase in $\mathrm{CO}_{2}$ concentration averaged $0.30 \% \mathrm{CO}_{2} \mathrm{~h}^{-1}$, which lies in the range of that observed under ant-made occlusion of all openings.

\section{Respiration rate of a colony}

A closed-loop system was used to investigate the effects of elevated $\mathrm{CO}_{2}$ concentration on colony respiration. There was a clear reduction in $\mathrm{CO}_{2}$ accumulation rate in the closed-loop system as a function of increasing $\mathrm{CO}_{2}$ concentration (Fig. 5: colony-produced). Any decrease in $\mathrm{CO}_{2}$ accumulation rate with time indicates either a $\mathrm{CO}_{2}$-induced reduction in colony metabolism or a loss of $\mathrm{CO}_{2}$ in the gas phase of the system (absorption by the clay or the plastic boxes).

In order to control for any $\mathrm{CO}_{2}$ sink, the $\mathrm{CO}_{2}$ concentration was artificially increased after removal of the colony. $\mathrm{CO}_{2}$ was injected with constant flow rates into one of the empty boxes (three different flow rates were used; for details see methods). The mean $\mathrm{CO}_{2}$ concentration at the beginning was $1.14 \%(\mathrm{SD} \pm 0.05 ; \mathrm{n}=5)$ and the flow rate of $326 \mathrm{ml} \mathrm{h}^{-1}$ $\mathrm{CO}_{2}$ (Fig. 5: injected) matched best the colony-produced increase in $\mathrm{CO}_{2}$ concentration. More important, irrespective of the flow rate used, a reduction of $0.45 \% \mathrm{CO}_{2} \mathrm{~h}^{-1}$ (SD $\pm 0.06 ; \mathrm{n}=5$ ) was found in the last $50 \mathrm{~min}$ before reaching the $7 \%$ level, indicating a sink of $\mathrm{CO}_{2}$ in the system which needs to be taken into account in the calculations.

The mean $\mathrm{CO}_{2}$ production rates of the colony as a function of $\mathrm{CO}_{2}$ concentration are presented in Figure 6. Two time intervals which correspond to two different concentration ranges were defined, in order to clarify the presentation of the

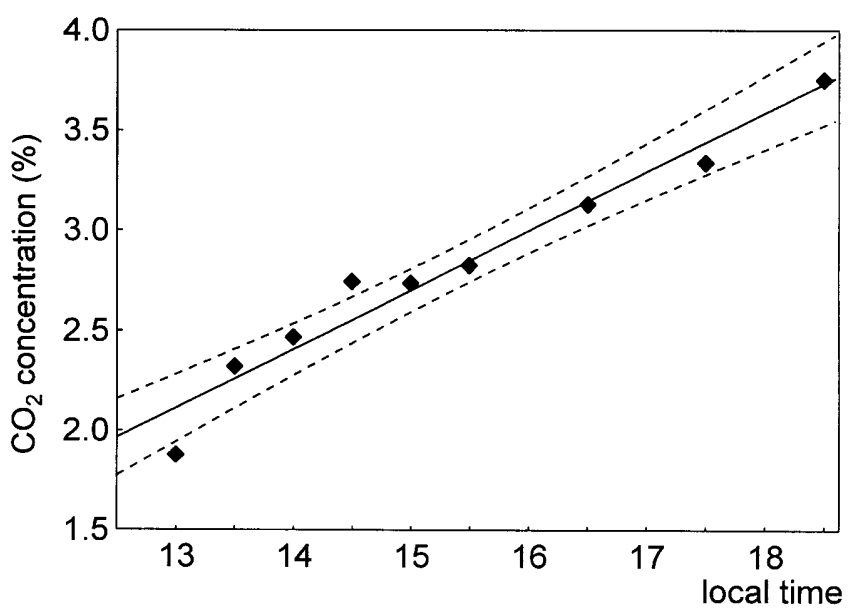

Figure 4. Increase of $\mathrm{CO}_{2}$ concentration in the small nest after artificial occlusion of all openings at 12:30 local time. Linear regression with $95 \%$ confidence interval of the slope (dotted line). Air samples for $\mathrm{CO}_{2}$ analysis were taken over six hours (sampling rate: $30 \mathrm{~min}$ in the first $3 \mathrm{~h}$; $60 \mathrm{~min}$ in the second $3 \mathrm{~h}$ )

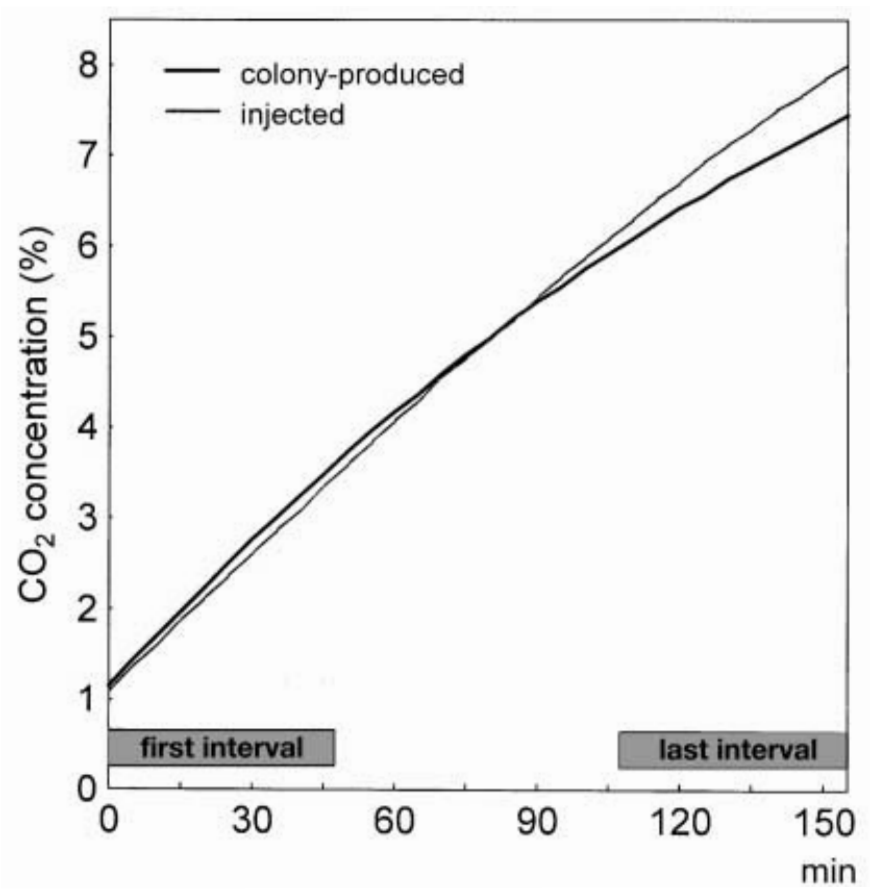

Figure 5. Example of the time-course of increasing $\mathrm{CO}_{2}$ concentration in the closed loop system for both colony-produced increase and artificial increase by injection. Any decrease in $\mathrm{CO}_{2}$ production or accumulation rate is expressed by a shallower slope. Horizontal bars indicate the intervals used for calculating the $\mathrm{CO}_{2}$ production rates shown in Figure 6

data. They were $50 \mathrm{~min}$ each and are indicated as horizontal bars at the bottom of Figure 5. In the experiment with the live colony, the mean $\mathrm{CO}_{2}$ concentration at the beginning was $1.17 \% \mathrm{CO}_{2}(\mathrm{SD} \pm 0.14 ; \mathrm{n}=6)$ and at the end $7.31 \% \mathrm{CO}_{2}(\mathrm{SD}$ $\pm 0.62 ; \mathrm{n}=6)$. The rate of $\mathrm{CO}_{2}$ production in the first $50 \mathrm{~min}$ (from $1.17-3.39 \% \mathrm{CO}_{2}$ ) was $2.98 \% \mathrm{CO}_{2} \mathrm{~h}^{-1}$, corresponding to $273 \mathrm{ml} \mathrm{h}^{-1}(\mathrm{SD} \pm 0.38 ; \mathrm{n}=6)$, and in the last $50 \mathrm{~min}$ (from 


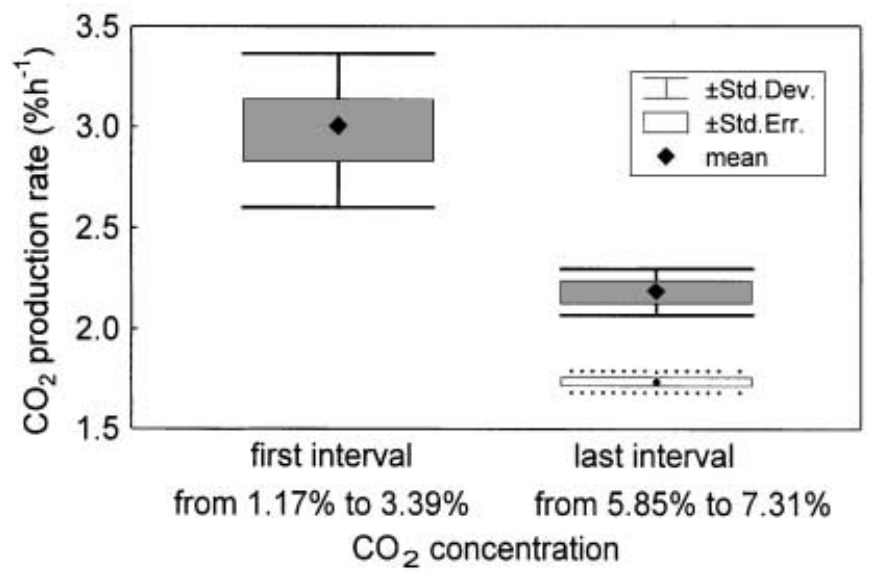

Figure 6. $\mathrm{CO}_{2}$ production rate of a small colony over $160 \mathrm{~min}$ in a closed-loop system. The $\mathrm{CO}_{2}$ production rate was calculated for the first interval shown on the left side (first $50 \mathrm{~min}$ ) and for the last interval on the right (last $50 \mathrm{~min}$, see Fig. 5). The dotted box/whisker (bottom right) indicates the $\mathrm{CO}_{2}$ production rate before correction with a factor of $0.45 \% \mathrm{CO}_{2} \mathrm{~h}^{-1}$ for the buffer capacity of the system

$\left.5.85-7.31 \% \mathrm{CO}_{2}\right)$ it was $1.74 \% \mathrm{CO}_{2} \mathrm{~h}^{-1}$, corresponding to $160 \mathrm{ml} \mathrm{h}^{-1}(\mathrm{SD} \pm 0.06 ; \mathrm{n}=6)$ (Fig. 6; left and lower right). The reduction of $0.45 \% \mathrm{CO}_{2} \mathrm{~h}^{-1}$, measured by injection of $\mathrm{CO}_{2}$ and used for correction of the colony-produced rate, is also presented in Figure 6 (upper right; error and deviation added).

Compared to the $\mathrm{CO}_{2}$ production rate of the colony at the beginning $\left(2.98 \% \mathrm{CO}_{2} \mathrm{~h}^{-1}\right)$ the resulting production rate at the end of the experiment $\left(2.18 \% \mathrm{CO}_{2} \mathrm{~h}^{-1}\right)$ represents a reduction of $27 \%$.

\section{Discussion}

\section{$\mathrm{CO}_{2}$ concentrations}

Atta vollenweideri nests are subdivided into a living area with fungus chambers and an area with dump chambers. The fungus chambers are located above the dump chambers and have never been found at depths greater than $2 \mathrm{~m}$ (Jonkman, 1980a). In contrast to the fungus chambers, the dump chambers are located at different depths depending on nest age and location (Jonkman, 1980b). The air probes from the upper part of the mature nests can therefore be considered as probes from the area with fungus chambers and those from the lower part as probes from the area with dump chambers.

In the area with fungus chambers, the $\mathrm{CO}_{2}$ concentration with a mean of less than $1 \% \mathrm{CO}_{2}$ was low. In the area of the dump chambers it was $2 \%$, being therefore higher and in the range of concentrations measured in the nests of the ant Formica polyctena, which lives in temperate zones (Kirchner, 1998). However, the $\mathrm{CO}_{2}$ concentrations inside the nest were lower than expected, since the site of production, the fungus chambers, are far below the nest surface. This indicates that mature nests are generally well ventilated, irrespective of the variability in nest shape and wind conditions in between measurements.
The high variability of the measured $\mathrm{CO}_{2}$ concentrations probably reflects the fact that the probe could not be selectively inserted into a chamber, and that thus some air probes may have been taken from tunnels connecting the chambers.

\section{Ventilation}

$\mathrm{CO}_{2}$ concentration was used as a measure for ventilation because it allowed the measurement of gas concentration inside the nest without destroying any nest structures. The hole which was drilled into the nest was only $14 \mathrm{~mm}$ wide and small injuries to the nest are normally quickly repaired by the ants. Measurement using IR-absorption is fast, only small amounts of air have to be drawn from the nest and ventilation is thus minimally influenced.

Surface wind was observed to induce the exchange of air in the tunnels of the nest. In both nests, the strong negative correlation between wind velocity and $\mathrm{CO}_{2}$ concentration illustrates the significance of wind as the driving-force for ventilation. In the literature, thermal convection is still the proposed mechanism for nest ventilation (Weber, 1972; Hölldobler and Wilson, 1990), and wind-induced ventilation was so far not adequately considered. Wind may either force air into the tunnel system on the upwind side or draw it from openings parallel to wind direction on top of the mound. The latter was observed to be the case which results in airflow within the nest. During summer, air leaves the nest through tunnel openings at the center of the mound, and consequently fresh air enters the nest through openings at the periphery (Kleineidam, unpublished).

\section{Temperature and humidity}

The conditions for optimum growth of the attine symbiont fungus are condensing humidity and temperatures of about $25^{\circ} \mathrm{C}$; temperatures higher than $30^{\circ} \mathrm{C}$ are lethal (Quinlan and Cherrett, 1978; Powell and Stradling, 1986). At a depth where fungus chambers occur, the relative humidity in the nests was always above $90 \%$, so that the ventilation demands of the colony during summer do not compromise the humidity conditions inside the nest. Although the air in some tunnels near the surface and $40 \mathrm{~cm}$ into the ground was hot and of low relative humidity, these daily local fluctuations did not affect the nest at large. Due to the great surface area in the tunnels and the high water content of the soil, inflowing air was cooled down which resulted in an increase in relative humidity. Temperatures in tunnels $1 \mathrm{~m}$ below surface were never above $30^{\circ} \mathrm{C}$, confirming the results of previous investigations in nests of Atta (Weber, 1959). It remains to be shown whether by controlling nest ventilation the ants adjust temperature conditions inside the chambers to suit the fungus demands, or whether the fungus is adjusted to the prevailing temperature conditions.

Temperatures lower than $25^{\circ} \mathrm{C}$ are suboptimal for the colony, and leaf-cutting ants are able to upregulate low temperatures in their fungus garden. How successful they are in incubating their fungus garden was shown for Acromyrmex 
ambiguus in the Argentine pampa, where the fungal garden was heated up to more than $10^{\circ} \mathrm{C}$ above soil temperature (Weber, 1972). Suboptimal temperatures primarily inhibit or reduce brood development, which directly influences the growth rate of a colony (Himmer, 1927; Porter, 1988).

For Atta vollenweideri with the southernmost distribution within the Attini, nest temperature may be a decisive factor for colony growth in winter when environmental temperatures are below $17^{\circ} \mathrm{C}$ (mean in August). Reduction of the number of openings during winter, with a concomitant reduction in ventilation, may lead to an increase of nest temperature in mature nests, an aspect which remains to be demonstrated. With restricted temperature tolerance and high relative humidity demands, the Atta symbiont appears to set the limits within which optimal colony growth rates can be achieved.

\section{Nest closure of small colonies}

Heavy rain in summer induces a conspicuous reaction in small colonies, namely occlusion of all nest openings. During the growth phase, which is defined as the time when nest surface area increases exponentially (Jonkman, 1980a), small nests are not protected against flooding because of their shallow nests. Even though the nests have drainage tunnels and may absorb some inflowing rain, they are unsuited as protection against flooding. Hence, a young colony has to close all openings and to sustain occlusion of the nest for several days. Many leaf-cutting ants species, including Atta vollenweideri (Jonkman, 1980a), build turrets upon the nest openings, which are supposed to serve as protection against inundation (Navarro and Jaffe, 1985). However, the turrets may also enhance wind-induced ventilation, because of their several holes exposed to higher wind velocities. At the study site, turrets were observed to occur only in the center of the nest mounds of mature Atta vollenweideri colonies.

Small nests are usually flat at the top and following rain, puddles can often be observed for several hours above former openings. In contrast, the shape of mature nests facilitates the drainage of water. Thus, precipitation represents a stronger stress factor for small than for mature colonies. They do not need to close the nest openings in this situation, but small colonies have to handle the tradeoff between inundation and ventilation during rainy periods. Enclosure of the dwellings leads to an immediate increase of $\mathrm{CO}_{2}$ concentration inside the nest. As a consequence, the $\mathrm{O}_{2}$ concentration decreases due to respiration. Postulating a respiratory exchange ratio between oxygen and carbon dioxide (RQ) of 1 for the whole colony, a concentration of $5 \% \mathrm{CO}_{2}$ in the nest would indicate a reduction of $25 \%$ in the partial pressure of $\mathrm{O}_{2}$. The decline of $\mathrm{O}_{2}$ and rise of $\mathrm{CO}_{2}$ depend not only on the respiratory exchange ratio of the colony but also on soil properties. Due to the solubility of $\mathrm{CO}_{2}$ in water in the soil, the measured increase in $\mathrm{CO}_{2}$ concentration may lead to an underestimation of the actual rate of $\mathrm{CO}_{2}$ production by the colony. Consequently, even much lower $\mathrm{O}_{2}$ concentrations may indeed occur in the nests than those expected from the $\mathrm{CO}_{2}$ measurements, as shown for burrows of the mole rat (Arieli, 1979).

\section{Colony respiration}

The cultivation of the fungus by ants and the biochemical interactions between the two symbiotic partners are extremely complex (Schildknecht and Koob, 1970; Iwanami, 1978). This was the reason why the respiration of the whole colony (fungus, workers, and brood) and not that of the isolated participants was investigated in the laboratory experiments. When the ants are removed, the symbiotic fungus quickly degenerates (Martin, 1987). The two Atta species A. sexdens and $A$ vollenweideri probably cultivates a diversity of cultivars of the fungal symbiont (Leucocoprinus gongylophorus), and it has been suggested that due to the clonal nature of the fungus, species-specific fungal strains are likely to evolve quickly (Stradling and Powell, 1986; Chapela et al., 1994; Mueller et al., 1998). In fact, different nests of the same ant species may have different strains and each nest appears to have only a single strain (Mueller U.G. pers. comm.). In addition, the cultivars of both ant species may be adapted to the different foraging habits (monocots vs. dicots), the distinct habitats, as well as to other parameters correlating to these differences. For example, a generally drier habitat (where $A$. vollenweideri lives) may necessitate reduced ventilation, and thus cause higher $\mathrm{CO}_{2}$ levels and increased selective pressure to tolerate high $\mathrm{CO}_{2}$ concentrations. In addition, the fungal metabolism of the collected leaves may change at high $\mathrm{CO}_{2}$ concentrations. Thus, the results obtained with the laboratory colony of $A$. sexdens should only illustrate a general effect of high $\mathrm{CO}_{2}$ concentration on colony respiration.

It should be noted that in this study no experimental separation between the effects of reduced $\mathrm{O}_{2}$ or increased $\mathrm{CO}_{2}$ concentration on colony respiration could be made, since any increase in $\mathrm{CO}_{2}$ concentration was accomplished with a parallel decrease in $\mathrm{O}_{2}$ concentration. Literature data, however, allow to split and discuss the potential effects of each of the gases, separately, on the respiration of workers and fungus. Regarding to the workers, measurements under hypoxic conditions showed that respiratory regulation allows Atta sexdens workers to maintain respiratory rates down to an $\mathrm{O}_{2}$ concentration of $10 \%$ (normoxia 21\% $\mathrm{O}_{2}$ ) (Hebling et al., 1992). Therefore, no changes in respiration rates of the ants are expected to occur in the closed-loop experiment with low $\mathrm{O}_{2}$ and high $\mathrm{CO}_{2}$ concentrations, and observations indicated no noticeable changes in ant activity during the recording period.

Regarding to the fungus, a possible effect of increased $\mathrm{CO}_{2}$ concentrations on its growth is the change in acidity of the substrate. Although the $\mathrm{pH}$ in the fungus garden was not measured, it is unlikely that acidity due to dissolved $\mathrm{CO}_{2}$ in water (as $\mathrm{H}^{+}$and $\mathrm{HCO}_{3}^{-}$) increased to fungus-inhibiting levels. During the closed-loop experiment the $\mathrm{CO}_{2}$ concentration was increased only for $3 \mathrm{~h}$ per day, and acidity control by the ants in the fungus garden was assumed (Powell and Stradling, 1986).

Based on these arguments, it is suggested that decreased $\mathrm{O}_{2}$ concentration, due to the lack of ventilation, immediately leads to suboptimal $\mathrm{O}_{2}$ supply for the fungus. In closed nests with reduced exchange of respiratory gases, the decrease in 
the $\mathrm{CO}_{2}$ respiratory rate is therefore likely to be caused mainly by a reduced respiration of the symbiotic fungus.

In conclusion, the nest architecture of mature Atta vollenweideri colonies ensures a good microclimate for the fungus concerning temperature and humidity. Wind-induced ventilation promotes the exchange of respiratory gases and keeps $\mathrm{CO}_{2}$ concentrations inside the nest at low levels. Small colonies suffer reduced exchange of respiratory gases while closing their nest as a response to heavy rain. As a consequence, the respiration rate of the colony is reduced, compromising colony growth. Small colonies are therefore confronted with a tradeoff between minimizing the risk of inundation and assuring adequate gas exchange in their nests.

\section{Acknowledgments}

The research reported here was supported by the DFG (grants SFB 251 and GK "Grundlagen des Arthropodenverhaltens") and DAAD, Germany (grant from the PWA program with the "Fundación Antorchas", Argentina). We are deeply grateful to the administration of the Parque Nac. Río Pilcomayo, Argentina, Néstor Sucunza and the Guardaparques for providing space and facilities at their wonderful field station 'Estero Poí'. We thank Roman Ernst who was involved in planning the experimental design and developing experimental equipment and Gudrun Herzner for experimental support. Anja Weidenmüller, Josué Núñez and Ulrich Mueller carefully read several versions of the manuscript and gave helpful comments.

\section{References}

Anderson, J.F. and G.R. Ultsch, 1987. Respiratory gas concentration in the microhabitats of some Florida arthropods. Comp. Biochem. Physiol. 88A: 585-588.

Arieli, R., 1979. The atmospheric environment of the fossorial mole rat (Spalax ehrenbergi): effects of season, soil texture, rain, temperature and activity. Comp. Biochem. Physiol. 63A: 569-575.

Chapela, I.H., S.A. Rehner, T.R. Schultz and U.G. Mueller, 1994. Evolutionary history of the symbiosis between fungus-growing ants and their fungi. Science 266: 1691-1694.

Collins, M.S., 1969. Water relations in termites. In: The Biology of Termites, vol. 1 (K. Krishna and F.M. Weesner, Ed.), Academic Press, New York, pp. 433-458.

Daguerre, J.B., 1945. Hormigas del genero Atta de la Argentina (Hym.: Formicidae). Rev. Soc. Ent. Argentina 12: 438-460.

Eidmann, H., 1935. Zur Kenntnis der Blattschneiderameise Atta sexdens. Z. ang. Entomol. 22: 185-241.

Es'Kov, E.K., 1974. The hives microclimate and the bee colony's biological condition. Pchelovodstvo 94: 19-21.

Hebling, M.J.A., C.H.S. Penteado and E.G. Mendes, 1992. Respiratory regulation in workers of the leaf cutting ant Atta sexdens rubropilosa Forel, 1908. Comp. Biochem. Physiol. 101A: 319-322.

Himmer, A., 1927. Ein Beitrag zur Kenntnis des Wärmehaushalts im Nestbau sozialer Hautflügler. Z. vergl. Physiol. 5: 375-389.

Hölldobler, B. and E.O. Wilson, 1990. The Ants. Belknap Press of Harvard University Press, Cambridge, Mass., 732 pp.

Howarth, F.G., 1983. Ecology of cave arthropods. Ann. Rev. Entomol. 28: $365-389$.

Iwanami, Y., 1978. Myrmicacin, a new inhibitor for mitotic progression after metaphase. Protoplasma 95: 267-271.

Jonkman, J.C.M., 1978. Population dynamics of leaf-cutting ant nests in a Paraguayan pasture. Z. ang. Ent. 87: 281-293.

Jonkman, J.C.M., 1979. Distribution and densities of the leaf-cutting ant Atta vollenweideri Forel, 1893 in Paraguay. Z. ang. Ent. 88: $27-43$.
Jonkman, J.C.M., 1980a. The external and internal structure and growth of nests of the leaf-cutting ant Atta vollenweideri Forel, 1893 (Hym.: Formicidae) Part I. Z. ang. Ent. 89: 158-173.

Jonkman, J.C.M., 1980 b. The external and internal structure and growth of nests of the leaf-cutting ant Atta vollenweideri Forel, 1893 (Hym.: Formicidae) Part II. Z. ang. Ent. 89: 217-246.

Kirchner, W., 1998. Schlechte Luft in Waldameisennestern? Ameisenschutz aktuell 12: 33-46.

Kleineidam, C. and J. Tautz, 1996. Perception of carbon dioxide and other "air-condition" parameters in the leaf cutting ant Atta cephalotes. Naturwissenschaften 83: 566-568.

Lüscher, M., 1956. Die Lufterneuerung im Nest der Termite Macrotermes natalensis (Haviland). Insectes soc. 3: 273-276.

Lüscher, M., 1961. Air-conditioned termite nests. Sci. Am. 205: $138-145$.

Martin, M.M., 1987. The symbiosis between the attine ants and the fungi they culture in their nest. In: Invertebrate-Microbial Interactions (M.M. Martin, Ed.), Cornell University Press, Ithaca, London, pp. 91-141.

Matsumoto, T., 1977. Respiration of fungus comb and $\mathrm{CO}_{2}$ concentration in the center of mounds of some termites. Proc. 8th IUSSI Cong.: 104-105.

Mueller, U.G., S.A. Rehner and T.R. Schultz, 1998. The evolution of agriculture in ants. Science 281: 2034-2038.

Navarro, J.G. and K. Jaffe, 1985. On the adaptive value of nest features in the grass-cutting ant Acromyrmex landolti. Biotropica 17: $347-348$.

Noirot, C., 1970. The nests of termites. In: The Biology of Termites, vol. 2 (K. Krishna and F.M. Weesner, Ed.), Academic Press, New York, pp. 37-125.

Porter, S.D., 1988. Impact of temperature on colony growth and developmental rates of the ant, Solenopsis invicta. J. Insect Physiol. 34: $1127-1133$.

Powell, R.J. and D.J. Stradling, 1986. Factors influencing the growth of the Attamyces bromatificus, a symbiont of Attine ants. Trans. Br. Mycol. Soc. 87: 205-213.

Pujalte, J.C., A.R. Reca, A.R. Balabusic, P. Canevari, L. Cusato and V.P. Fleming, 1995. Unidades Ecológicas del Parque Nacional Río Pilcomayo, vol. XVI. Administración de Parques Nacionales, Buenos Aires, $185 \mathrm{pp}$.

Quinlan, R.J. and J.M. Cherrett, 1978. Aspects of the symbiosis of the leaf-cutting ant Acromyrmex octospinosus (Reich) and its food fungus. Ecol. Entomol. 3: 221-230.

Scherba, G., 1958. Moisture regulation in the mound nests of the ant Formica ulkei (Emery). American Midland Naturalist 61: 499-508.

Schildknecht, H. and K. Koob, 1970. Plant bioregulators in the metathoracic glands of myrmicine ants. Angew. Chemie Int. Ed. 9: 173.

Seeley, T. and B. Heinrich, 1981. Regulation of temperature in the nests of social insects. In: Insect Thermoregulation (B. Heinrich, Ed.), John Wiley \& sons, INC., New York, pp. 159-234.

Seeley, T.D., 1974. Atmospheric carbon dioxide regulation in honey-bee (Apis mellifera) colonies. J. Insect Physiol. 20: 2301-2305.

Siegel, S. and N.J. Castellan, 1988. Nonparametric Statistics for the Behavioural Sciences. 2. McGraw-Hill, New York, 399 pp.

Simpson, J., 1961. Nest climate regulation in honebee colonies. Science 133: 1327-1333.

Southwick, E.E. and R.F.A. Moritz, 1987. Social control of air ventilation in colonies of honey bees, Apis mellifera. J. Insect Physiol. 33: 623-626.

Stradling, D.J. and R.J. Powell, 1986. The cloning of more highly productive fungal strains: a factor in the speciation of fungus-growing ants. Experientia 42: 962-964.

Weber, N.A., 1959. Isothermal conditions in tropical soil. Ecology 40: $153-154$

Weber, N.A., 1972. Gardening Ants the Attines. The American Philosophical Society, Philadelphia, $146 \mathrm{pp}$.

Withers, P.C., 1978. Models of diffusion-mediated gas exchange in animal burrows. Am. Nat. 112: 1101-1112. 